\title{
EVALUATION OF NORPALNT IN NEPALESE WOMEN
}

BHARATI U. ${ }^{1}$
SHRIVASTAVA V. ${ }^{2}$

\section{ABSTRACT:}

This was a prospective study done in Marie Stope clinic, Chabhill, Kathmandu. One hundred women who had Norplant insertion between May 1996 to April 1997 were followed up for a year for its side effects. The age, ethnic group, number of living children, literacy, socioeconomic status of the women who has Norplant insertion were also analyzed. Norplant was found to be most popular in age group of 21-30 years $(68 \%)$. Maximum number of acceptors were in Chetri community $(32 \%)$. It was a popular contraceptive in women who had two or more children and those who came from low socioeconomic group and were illiterate. Among side effects, menstrual irregularity was commonest $(67 \%)$ headache was present in $12 \%$, weight gain and depressive symptoms each was present in $10 \%$ of women. $2 \%$ had local infection at insertion site and $1 \%$ of woman had allergic reaction.

\section{Key words: Norplant, Contraceptives, Side effects.}

\section{INTRODUCTION:}

Population growth is one of the major problems in Nepal. According to last census in 1991, the growth rate of Nepal is $2.1 \%$ which means that Nepalese population is going to double in 26 years time. This is less than half of the duration which was required for last doubling of population between 1911-1971.

The most important reasons for this population growth are high birth rate and declining death rate. The reasons behind high birth rate are poverty, low literacy, lack of awareness and unavailability of family planning method.

Although, according to the recent survey (FHS 1996) about $98 \%$ of women are aware of at least one method of family planning, only $35 \%$ of them are currently using any of them. Permanent sterilization has remained the most popular method. Over the years the use of contraceptives has increased. The increase is mainly in the use of DepoProvera and Norplant.

\section{OBJECTIVE:}

The main objective of this study was to see in which group and type of population Norplant is popular and to assess the type and frequency of side effects they experience after Norplant insertion.

Norplant is basically Levonorgestrel kept in six small silastic sticks which are implanted subdermally in upper arm. It slowly releases progesterone in the circulation. It acts by suppressing ovulation. It makes cervical mucus thick so that sperm can not penetrate it. Norplant is effective for five years and has less than one percent failure rate.

\section{METHODOLOGY:}

It was a prospective study which was done in Marie Stopes Clinic, Chabhill. One hundred clients who had Norplant insertion between the period of May 1996 to April 1997 were followed up for one year.

1. Asst. Prof. Department of General Practice, NMCTH, Jorpati, Kathmandu, Nepal.

2. Asst. Prof. Department of General Practice, NMCTH, Jorpati, Kathmandu, Nepal. 
The side effects experienced by them in one-year time were recorded. The age group, cast, social and educational status and parity of the women who had Norplant insertion were also analyzed.

\section{RESULTS:}

The results of the study are shown in following tables.

\section{Table 1 showing the ethnic group:}

\begin{tabular}{|l|l|l|}
\hline Ethnic Group & Numbers & Percentage \\
\hline Brahmin & 26 & $26 \%$ \\
\hline Chetri & 32 & $32 \%$ \\
\hline Newars & 17 & $17 \%$ \\
\hline Others & 25 & $25 \%$ \\
\hline Total & 100 & $100 \%$ \\
\hline
\end{tabular}

This table shows Norplant users were highest in Chetri ethnic groups.

Table 2 showing Age distribution of Norplant acceptors

\begin{tabular}{|l|l|l|}
\hline Age Group & Numbers & Percentage \\
\hline Up to 20 years & 15 & $15 \%$ \\
\hline $21-30$ & 68 & $68 \%$ \\
\hline $31-40$ & 17 & $17 \%$ \\
\hline Total & 100 & $100 \%$ \\
\hline
\end{tabular}

Maximum number of Norplant acceptors was in 20-30 age groups. The lowest age of Norplant acceptor was 17 and the highest age was 40 .

\section{Table 3 showing relation with education of} Norplant acceptors:

\begin{tabular}{|l|l|l|}
\hline Education & Number & Percentage \\
\hline Literate & 40 & $40 \%$ \\
\hline Illiterate & 60 & $60 \%$ \\
\hline Total & 100 & $100 \%$ \\
\hline
\end{tabular}

One who can read and write is considered literate in our study.

Table 4, showing the number of living children of Norplant acceptors:

\begin{tabular}{|l|l|l|}
\hline Number of children & Number & Percentage \\
\hline One & 15 & $15 \%$ \\
\hline Two & 55 & $55 \%$ \\
\hline Three & 20 & $20 \%$ \\
\hline More than three & 10 & $10 \%$ \\
\hline Total & 100 & $100 \%$ \\
\hline
\end{tabular}

Norplant was more popular in those women who had completed their family.

Table 5, showing economical status of Norplant acceptors:

\begin{tabular}{|l|l|l|}
\hline Economical & Num. & Per. \\
\hline Lower socioeconomic group & 60 & $60 \%$ \\
\hline Middle socioeconomic group & 30 & $30 \%$ \\
\hline High socioeconomic group & 10 & $10 \%$ \\
\hline Total & 100 & $100 \%$ \\
\hline
\end{tabular}

Norplant was found most popular in lower socioeconomic group.

Table 6, showing side effects experienced by Norplant acceptors:

\begin{tabular}{|l|l|l|}
\hline Side effects & Num. & Per. \\
\hline Changes in menstrual cycle & 65 & $65 \%$ \\
\hline headache & 12 & $12 \%$ \\
\hline Weight gain & 10 & $10 \%$ \\
\hline Depressive symptoms & 10 & $10 \%$ \\
\hline Breast pain & 2 & $2 \%$ \\
\hline $\begin{array}{l}\text { Local infection in } \\
\text { implantation site }\end{array}$ & 2 & $2 \%$ \\
\hline Local allergic reaction & 1 & $1 \%$ \\
\hline
\end{tabular}


Table 7, showing different types of contraceptives accepted during May 1996 to April 1997.

\begin{tabular}{|l|l|}
\hline Contraceptives & Number \\
\hline Female voluntary sterilisation & 329 \\
\hline Intra uterine contraceptive device & 30 \\
\hline Depo provera & 527 \\
\hline Oral contraceptive pills & 610 \\
\hline Condoms & 8260 \\
Norplant & 100 \\
\hline \hline
\end{tabular}

\section{DISCUSSION:}

Norplant consists of six small flexible capsules made of silastic tube, which contain synthetic progesterone (Levonorgestrel). These capsules are surgically implanted under the skin of woman's upper arm. These implants slowly release progesterone in the circulation and provide contraceptives protection for five years. It is effective within 24 hours of insertion and normal fertility returns within 24 hours of its removal. It prevents pregnancy by making cervical mucus thick and suppressing the ovulation.

Norplant was found to be the fifth popular contraceptive method family planning (Table 7) among the women coming to our centre. The maximum number of Norplant insertion was in the 21-30 age group (Table 2). Norplant was more popular in Chetri community. (Table 1.32\%). The reason is not known. Perhaps the area served by our centre has more Chetris. Higher number of Norplant acceptors were in illiterate people (Table $3-63 \%$ ). This could be due to selection of a method, which does not require every day or very frequent personal involvement of the client, and at the same time a long-term family planning protection given by Norplant. Norplant was found to be a popular contraceptive method in those women who had completed their family. (Table 4). These women were those who did not want to have any further children and at the same time due to various reasons, did not want to have permanent sterilization.

In our study Norplant was found to be a popular method of contraception among the poor people
(Table 6). Who's monthly income is less the 1600 (sixteen hundred) rupees.

Among the side effects experienced by the hundred women studies, menstrual problem was the commonest (Table 7.65\%). 21\% women came back with the complain of bleeding persistent for one week, $39 \%$ for more than two weeks and $27 \%$ developed for more than three weeks. $7 \%$ of women amenorrhoea. Those who complained of bleeding were given a course of NSAID (Brufen $400 \mathrm{mg}$ three times daily for 5 days). All of them responded well to the treatment. Increased and prolonged bleeding during first ninety days of Norplant insertion is a commonest side effect (83\% in a study done in Florida, $65 \%$ in a study done in Indonesia $)^{1,2}$. Bleeding usually decreases with time and is less problematic by the end of one year.

Headache is the second most common side effect experienced by Norplant users of our study. It was present in $12 \%$ of cases and was of mild type.

Weight gain was noted in $10 \%$ of Norplant users. Among 10 women, 3 had more than $3 \mathrm{~kg}$ weight gain. within 6 months of Norplant insertion. 7 women had less than $3 \mathrm{~kg}$ weight gain.

Depressive symptoms were experienced by $10 \%$ of Norplant users. 2\% women complained of breast pain and same number of women had local infection at insertion site. Local allergic reaction necessitating removal of Norplant was present in $1 \%$ of case.

No case of acne, jaundice, ectopic pregnancy and lower abdominal pain was noted in our study.

\section{Conclusion:}

Norplant is highly effective, safe and economic family planning method. It is popular more in lower socioeconomic class, illiterate and young women (21-30) who had completed their family. The most common side effects of Norplant are irregular uterine bleeding which is usually controlled by the end of one year. Simple medication as NSAID and haematinic are enough to control the bleeding. Proper counseling about the side effects is essential so that 
client can cope with it in better0prepared way. Headache, weight gain, depression, local infection and allergic reaction are other minor side effects which a Norplant user might experience. No ectopic pregnancy, jaundice, acne was noted in our study.

\section{Reference:}

1. Family Health Survey: Department of Health Services, Family Health Division of Kathmandu Nepal 1996.

2. GUSJ: Du MK et al: A 5 year evaluation of Norplant contraceptives implants: Obstet Gynecol 1994 May Vol. 83 673-8.

3. Dr. Peter Rosers: Resolving contraceptives issues in the $3^{\text {rd }}$ world: Dept. of Obstet. \& Gynacology in Monash's University of Indonesia: Monash Publication.

4. N M cintosh, A Blouse, L Schafer: Norplant guidelines for family planning service programme: $2^{\text {nd }}$ edition.

5. $\mathrm{K} \mathrm{R}$ Pandey, $\mathrm{H}$ Shrestha, H La,a" Restrospective study of Norplant acceptors in districts of Nepal: Journal of Nepal Medical
Association: Vol 32, Number 109, Jan-March 1994.

6. Hem Raj Regmi- Family Planning uses and obstacles - Four Monthly Statistical Bulletin 2053/54.

7. National Medical Standard for Reproductive Health Contraceptive Services Vol 1 His Majesty's Government Ministry of Health, Family Division 1995.

8. Chhetri M K, Lama H: Norplant an Introduction and Experiences in Nepal, 1987.

9. Clarke LL, Schmitt K, Bano CA, Steele J: Miller MK Norplant Selection and satisfaction among low income women. AMJ Public Health, 1998 Aug. 88:8, 1175-81. Department of Health Policy and Epidemiology, university of Florida, Gainesville 32610 0177, USA.

10. Nita Pokherel - A study on contraceptive use and effectiveness as expressed by the women of Kathmandu Nepal Journal of Nursing Education Nepal Vol 1 No 1 April 1998. 